\title{
Silane Terminated Prepolymers: An Alternative to Silicones and Polyurethanes
}

\author{
Ravindra V. Gadhave ${ }^{1}$, Chaitali R. Gadhave ${ }^{2}$, Pritam V. Dhawale ${ }^{1}$ \\ ${ }^{1}$ Department of Polymer and Surface Engineering, Institute of Chemical Technology, Mumbai, India \\ ${ }^{2}$ Department of Microbiology, Savitribai Phule Pune University, Pune, India \\ Email: ^ravi.gadhave3@gmail.com
}

How to cite this paper: Gadhave, RV., Gadhave, C.R and Dhawale, P.V. (2021) Silane Terminated Prepolymers: An Alternative to Silicones and Polyurethanes. Open Journal of Polymer Chemistry, 11, 31-54. https://doi.org/10.4236/ojpchem.2021.113003

Received: August 19, 2021

Accepted: August 27, 2021

Published: August 30, 2021

Copyright ( 2021 by author(s) and Scientific Research Publishing Inc. This work is licensed under the Creative Commons Attribution International License (CC BY 4.0).

http://creativecommons.org/licenses/by/4.0/

\section{(c) (i) Open Access}

\begin{abstract}
Silane terminated prepolymers for adhesives, sealants and coatings are of great industrial importance. They are very important because of their low toxicity over polyurethanes, silicones, and solvent-based products. Hence, many pieces of literature which deal with the synthesis, properties and applications of this Silane terminated polymers hybrid system exist. Silylated polyether (MS polymers) and Silylated Polyurethane Polymers (SPUR) are the bases for numerous sealants, adhesives and coatings used worldwide. A hybrid system mixed with organic-polyurethane proportion and inorganic-alkoxysilane proportion combines the benefits of conventional polyurethane and silicone-based products. This article reviews the chemistry of MS polymers and SPUR and their advantages and disadvantages in silyl terminated prepolymer-based adhesives, sealants and coatings as well as provides information on different end applications.
\end{abstract}

\section{Keywords}

Silanes, Silane Terminated Polyethers, Silane-Terminated Polyurethanes, Adhesives, Sealants, Coatings

\section{Introduction}

\section{Hybrid Chemistry: Silane Terminated Prepolymers}

Silane-terminated prepolymers have been used as resins for sealants, adhesives, and coatings for over 30 years due to many reasons. "Silane terminated polymersHybrid" is of increasing interest because they can be formulated to provide the best properties of two or more families of polymeric materials while limiting their individual inherent weaknesses. The silyl terminated adhesives, sealants and coatings systems are also isocyanate-free systems. They also provide better adhesion, 
abrasion resistance, better stability and low-temperature extrudability than silicone and polyurethane sealants [1] [2].

Silane terminated prepolymers can be formulated into one-component, twocomponent, and isocyanate-free products, where, due to their low viscosity, solvents can be excluded. It is beneficial that the products cure without bubble formation even under unfavorable weather conditions. Nowadays, many wood flooring adhesives are based on silane terminated polymers, as are several assembly adhesives and exterior waterproofing systems. In these kinds of applications, the elasticity of the cured materials and their wide adhesion profile are of particular importance. Applications in which bonded joints or waterproofing membranes are exposed to high dynamic loads remain the domain of polyurethane chemistry. Recently, adhesives used in the automotive or white goods industry are, for example, Silane terminated polymers based, including waterproofing membranes for roofs, balconies, and patios. After curing, all these industrial adhesives, sealants and coatings are highly elastic and have high tear and tensile strength [3].

This article reviews the advantages and disadvantages of silyl terminated prepolymer-based adhesives, sealants and coatings and provides information on different end applications. Both silylated polyether (MS polymers) and Silylated Polyurethane Polymers (SPUR) are discussed here.

\section{An Overview of Silanes}

\subsection{Chemistry}

Silicon ( $\mathrm{Si}$ ) belongs to the main Group 14 (formerly IVA) with carbon (C), germanium $(\mathrm{Ge})$, tin $(\mathrm{Sn})$, and lead $(\mathrm{Pb})$ on the periodic table and it has four valence electrons. The difference between the two groups is a partial filling electron configuration of $3 \mathrm{~d}-5 \mathrm{~d}$ orbitals in Group 14 [4]. The empty $3 \mathrm{~d}$ orbital of Si makes it chemically different from other Group 14 elements, in terms of structure, reactivity and thereby physical and chemical properties [5] [6]. Carbon $\left({ }^{6} \mathrm{C}\right)$ is a typical non-metal and silicon $\left({ }^{14} \mathrm{Si}\right)$ is a metalloid, semi-metal (a semi-conductor). Silicon is found as silica and numerous silicates, aluminous silicates in earth. Carbon can form endlessly long chains with other carbon atoms $-(-\mathrm{C}-\mathrm{C}-)_{\mathrm{n}^{-}}$. Silicon can also bond to other silicon atoms $(-\mathrm{Si}-\mathrm{Si}-)_{\mathrm{n}}$ - but with far shorter chain length (only up to 2 - 3 units) and such compounds are, in contrary, unstable. This is owing to the $\mathrm{C}-\mathrm{C}$ bond energy ( $356 \mathrm{~kJ} / \mathrm{mol}$ ) which is much higher than the Si-Si bond energy (226 kJ/mol). However, Silicon can form indefinitely long chains, but with oxygen atoms to form a siloxane linkage (-O-Si-O- $)_{n}$ because of a very strong $\mathrm{Si}-\mathrm{O}$ bond energy $(286 \mathrm{KJ} / \mathrm{mol})$. Silicon compounds are more reactive than carbon compounds because of the presence of vacant $3 \mathrm{~d}$ orbital.

Organosilicon compounds are widely found in adhesives, coatings, caulks, and sealers. Other remarkable uses include both plant and agricultural control chemicals (fungicides and herbicides). The term silane, once limited to silicon hydrides, has grown to include functional silanes, where one or more hydrogen atoms are replaced by a radical such as $\mathrm{Cl}, \mathrm{F}, \mathrm{CH}_{3}$, etc. Silanes find extensive use as pre- 
cursors in the chemical industry, as reagent in the production of high purity silicon, as surface modifiers for adhesion of various coating, as the transition compound from organic to inorganic materials, as precursors in producing a range of products, including silicones, and many other uses [5].

Organo silanes are synthesized from $\mathrm{SiO}_{2}$, silica one of the most abundant materials in the earth through a series of reaction. Silica is reduced to silicon which reacts with hydrogen chloride to yield trichlorosilane, $\mathrm{HSiCl}_{3}$. Then, trichlorosilane reacts with alkene and finally followed by alcoholysis, i.e., reaction with alcohol, to form the functional silanes. A silane coupling agent, which is a trialkoxysilane, contains two functional groups at the ends of its molecular backbone, and which connect an unpolymerized resin matrix and an inorganic substrate (surface). A general formula or such bifunctional silane is $\mathrm{L}-\left(\mathrm{CH}_{2}\right)_{\mathrm{k}}-\mathrm{Si}-(\mathrm{OR})_{3}$, where $\mathrm{L}$ is an organofunctional group (e.g., methacrylate, acrylate, isocyanato, epoxy), and these groups provide the organic compatibility which allows the silane to form interpenetrating networks, or in the case of reactive organofunctional silanes, to co-react with the coating polymer and $\left(\mathrm{CH}_{2}\right)$ is a linker (spacer) group that $\mathrm{k}$ separates the organofunctional group and the $\mathrm{Si}$ atom. OR is a hydrolysable alkoxyl group (methoxy, ethoxy).

At ambient temperature, silane is activated by acid (acetic acid) to form silanol $(\mathrm{SiOH})$ before they can bond to the inorganic substrate. The general formula of an alkoxy silane shows two classes of moieties attached to the silicon atom: Alkyl and aryl silanes are utilized to improve gloss, hiding power, mixing time, and other properties related to improved pigment dispersion. Alkyl and aryl silanes are also utilized to provide hydrophobic surfaces in applications such as water repellents. The $\mathrm{X}$ represents alkoxy moieties, most typically methoxy or etho$\mathrm{xy}$, which react with the various forms of hydroxyl groups and liberate methanol or ethanol. These groups (Table 1 ) can provide the linkage with inorganic substrates, pigment, or filler to improve coating integrity and adhesion. The methoxy groups are also capable of reacting with hydroxy functional polymers [5] [6].

\subsection{Activation and Hydrolysis of Silane}

Organofunctional silanes contain two different reactive functional groups that can react and couple with various inorganic and organic materials. Thus, they act as adhesion promoters to join dissimilar materials. These functional silane coupling age nts are first activated by hydrolysis $(=\mathrm{SiOR}=\mathrm{SiOH})$ before they can bond, via hydroxyl groups on the substrate surface.

The first step of hydrolysis of silane to silanol $(=\mathrm{SiOH})$ takes place by the fast and reversible protonation of the alkoxy group of the silane at $\mathrm{pH} 4$ ash shown in Figure 1. Then, it undergoes a bimolecular nucleophilic substitution $\left(S_{N} 2\right)$ reaction at the central silicon atom. This first involves the backside attack by a water molecule (nucleophile) to the central silicon atom (electrophile), to give a penta-coordinate trigonal bipyramidal transition state. A new bond is then formed between the nucleophile and the silicon center, and a bond is cleaved between 
Table 1. Classification and uses of silanes [7].

Inorganic silanes

- Precursor to production of organ silanes

- Precursor to production of electronic and solar grade silicons

- Reducing agent

- Used to produce Integrated Circuit (IC) devices and electrical isolation for IC interconnects

\section{Amino silanes}

- Promotes adhesion to various substrates, serves as coupling agent, and is used as resin additives

- Used with sulphur and peroxide cured rubber, polyester, Polyolefins, styrenics and acrylics

- Used with ethylene to copolymerize for moisture induced coupling of polyethylene

- Used with polyethylene for moisture induced coupling

- Surface modifier for mineral fillers as plastics

\section{Epoxy silanes}

- Adhesion promoter

- Surface treatment for fillers and reinforcement fillers

\section{Methacryl silanes}

- Used for free-radical, crosslinked polyester, rubber, poly(olefins), styrenics, and acrylics

- Promotes adhesion and serves as coupling agent including moisture crosslinking of acrylics

- Coupling agent between fillers and fiberglass to resins

\section{Alkyl silanes}

- Silicone synthesis

- Hydrophobic surface treatment

\section{Phenyl silanes}

- Improves thermal stability of both surfaces and silane coupling agents

- Hydrophobic treatment of both surfaces and silane coupling agents

- Use in synthesis of silanes and siloxanes

\section{Organ chlorosilanes}

- Protecting agents for intermediates in pharmaceutical synthesis (methyl chlorosilanes)

- Use in synthesis of silanes and siloxanes

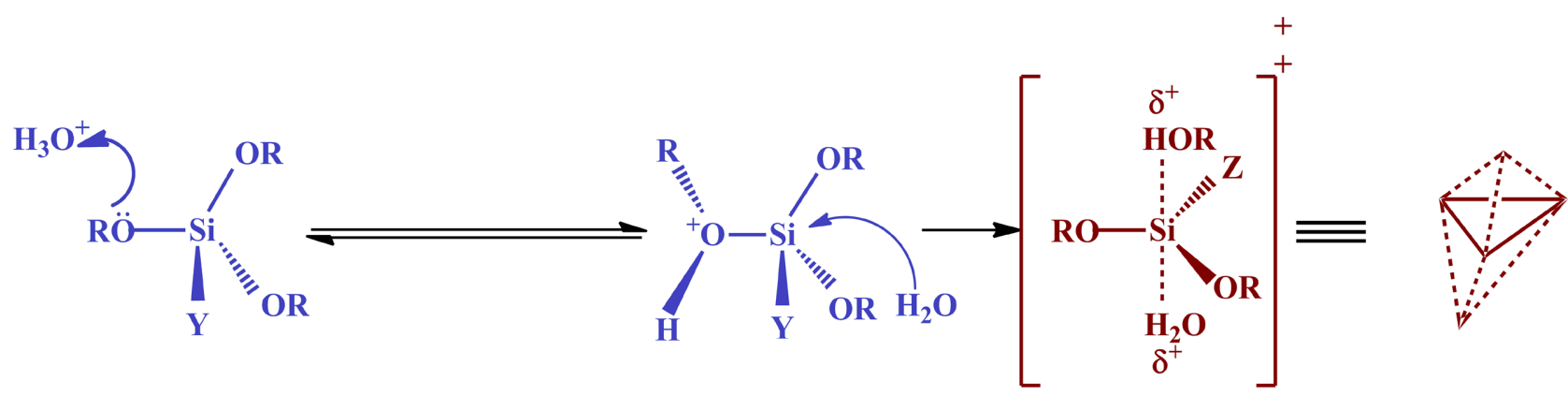

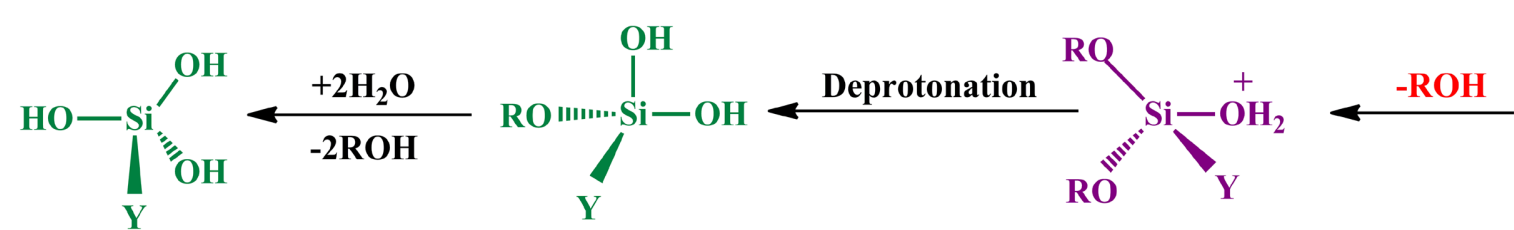

Complete Hydrolysis

Inversion of configuration

Figure 1. Silane hydrolysis mechanism in an acidic medium (OR is an alkoxy group and $\mathrm{Y}$ is an organofunctional group). 
the leaving group (alcohol) and the silicon center. Finally, this gives the product with inversion of configuration after the hydrolysis process [6] [7] [8].

\subsection{Factors Affecting Silane Hydrolysis}

The rate of silane hydrolysis depends among others on the silane molecular structure, its concentration, $\mathrm{pH}$, temperature, humidity, and solvent system. Ethanol is usually a part of the solvent system as silanes dissolve easily in ethanol but not in water. The bulkiness of alkoxy groups would affect the rate of hydrolysis. For silane coupling agents with bulky alkoxy groups, the steric repulsion of water moving towards to the silicon atom is increased as shown in Figure 2.

This said, the hydrolysis rate decreases with the large size of alkoxy groups: pentoxy $<$ butoxy $<$ propoxy $<$ ethoxy $<$ methoxy. The silane hydrolysis is strongly $\mathrm{pH}$ dependent. The silane hydrolysis rate is fast at acidic and alkaline medium, but it reaches a minimum at neutral $\mathrm{pH}$ for alkoxysilanes. Temperature is an important parameter: the hydrolysis reaction rate increases with temperature that follows the Arrhenius law. The hydrolysis rate is dependent on the nature of co-solvent in the solvent mixture. The hydrolysis rate depends on the hydrophilicity of the solvent. As the hydrophilicity decreases from methanol, ethanol, and propan-1-ol, the hydrolysis rate decreases [5] [9].

The silanes employed in improving adhesion and surface modification were usually alkoxysilanes. Before or during application and bonding processes alkoxysilanes were hydrolysed, initiating a complex cascade of reactions. In vast majority of silane surface treatment applications, the alkoxy groups of trialkoxy silanes were hydrolysed to form silane-containing species. The silanol-containing species were highly reactive intermediates which were responsible for bond formation with the substrate. Hydrolysis of trialkoxy groups may occur during formal preparation of aqueous solution or the reaction of the silane with adsorbed moisture on substrate surfaces. In principle, if silanol materials were stable, they would be preferred for surface treatments. Most silanes employed in surface treatments do not form stable monomeric silanols. Silanols usually condense

\section{Tripropoxyvinylsilane}

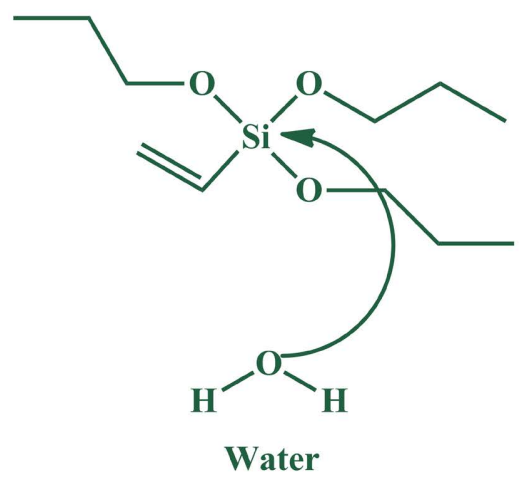

Tripmethopoxyvinylsilane

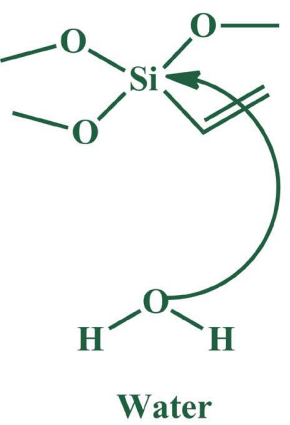

Figure 2. The steric effect of alkoxy groups on silane hydrolysis of tripropoxyvinylsilane and Trimethoxyvinylsilane. 
with themselves or with alkoxysilanes to form siloxanes. Trialkoxysilanes are stable sources for silanols, but they have low intrinsic viscosity, low solubility in aqueous solutions and by-products of hydrolysis which may be undesirable from a flammability and toxic perspective. Alkoxysilanes undergo hydrolysis by both base- and acid-catalysed mechanisms. In contact with high-purity $\left(18 \times 10^{6} \Omega \cdot \mathrm{cm}\right)$ water under neutral, low-ionic conditions in non-glass containers, alkoxysilanes bearing chlorosilanes and acetoxysilanes, the products of alkoxysilanes hydrolysis don't propagate the hydrolysis reaction. In contact with tap water hydrolysis of alkoxysilanes was substantial, if not complete within hours. The same factors which accelerate the hydrolysis of alkoxysilanes also accelerate the condensation of silanols with other silanols and their alkoxy precursor's [10].

\subsection{Classification of Silanes}

\subsubsection{Functional Silanes}

Organofunctional silanes contain two different reactive functional groups that can react and couple with various inorganic and organic materials. Thus, they act as adhesion promoters to increase the union of dissimilar materials. The hydrolysable functional groups react to the surface hydroxyl groups of inorganic substrates. The organic functional groups react with functional groups of resins (Table 2 ). Wide selections of the organofunctional groups of the silanes can react with different functional groups of dental resin composites. For example, epoxy resins with amino or epoxy silanes, vinyl or acrylate resins with vinyl or methacrylate silanes, etc.

\section{$a$-silanes and $\gamma$-silanes}

The relatively slow crosslinking kinetics of the standard silane terminated polymers are due to the molecular structure of the terminal silyl group. With

Table 2. Performance comparison of Silane terminated prepolymers, Polyurethane, and Silicone Sealants [43].

\begin{tabular}{lccc}
\hline \multicolumn{1}{c}{ Property } & $\begin{array}{c}\text { Silane terminated } \\
\text { prepolymers }\end{array}$ & Polyurethane & Silicone \\
\hline Environmental friendliness & 10 & 5 & 9 \\
Non-bubbling & 10 & 6 & 10 \\
Low temperature gunnability & 10 & 8 & 10 \\
Stain resistance & 8 & 8 & 5 \\
Weather resistance & 8 & 6 & 10 \\
Adhesion to various substrates & 10 & 5 & 8 \\
Mechanical properties & 10 & 8 & 10 \\
Heat resistance, mechanical stability & 9 & 10 & 10 \\
Non-dirt pickup & 10 & 7 & 5 \\
Storage stability & 10 & 10 & 9 \\
Paintability with water-based paint & 10 & & 3 \\
\hline
\end{tabular}


$\gamma$-alkoxysilanes, the moisture induced crosslinking reaction takes place considerably more slowly than with the highly reactive $\alpha$-alkoxysilanes. In $\alpha$-silanes, the electron donor is attached to the silicon atom via a methylene group. With this configuration, the alkoxy groups are activated, so that the crosslinking reaction is accelerated considerably. This is the difference between $\alpha$ and $\gamma$-silanes as shown in Figure 3, $\alpha$ - and $\gamma$-alkoxysilanes in organofunctional alkoxysilanes, at least one of the four groups bound to the silicon atom is an alkoxy group (-OR). Depending on the number of alkoxy groups, a distinction is made between bifunctional (two alkoxy group) and trifunctional silanes (three alkoxy group). The alkoxy groups are able to hydrolyze. The reaction with water leads to the formation of a siloxane network. In addition to the alkoxy groups, there is a functional organic group on the silicon atom (X). Via X, a silane can also bind to an organic molecule. This is how Silane-terminated prepolymers are produced. An important structural feature of organofunctional alkoxysilanes is the length of the hydrocarbon chain in the reactive organic group.

The $\gamma$-silanes used industrially so far contain a propyle ne group in their reactive organic group $\left(-\mathrm{CH}_{2}-\mathrm{CH}_{2}-\mathrm{CH}_{2}-\right)$ as spacer between the silicon ato $\mathrm{m}$ and the organofunctional group, so that $\mathrm{X}$ is in the $\gamma$-position (relative to the $\mathrm{Si}$ atom). In $\alpha$-silanes, the considerably shorter methylene group $\left(-\mathrm{CH}_{2}-\right)$ is located between the silicon atom and $\mathrm{X}$. In this case, $\mathrm{X}$ is $\boldsymbol{\alpha}$-terminal. The length of the hydrocarbon chain has a major influence on how firmly the alkoxy groups are bound to the silicon atom, and thus on the speed of crosslinking in the presence of moisture.

The $\alpha$-effect, in $\alpha$-alkoxysilanes, the reason for this effect is an electronic interaction between the silicon atom and the electron donor in the $\alpha$-position. As a result of back-bonding, the electron density is shifted from the donor to the silicon atom, and the $\mathrm{Si}-\mathrm{O}$ bonds are weakened. The alkoxy groups split off more easily and hydrolysis is accelerated [11].

\subsubsection{Non-Fun ction al Silanes}

Non-functional silanes contain only reactive alkoxy (-OR) functional groups that after hydrolysis to sila nol groups react with surface hydroxyl groups of inorganic substrates. A bis-functional silane has two silicon atoms, each containing three hydrolysable alkoxy groups and they are also called cross-linking or dipodal silane. The purpose of this cross-linking silane is to connect the silane molecules

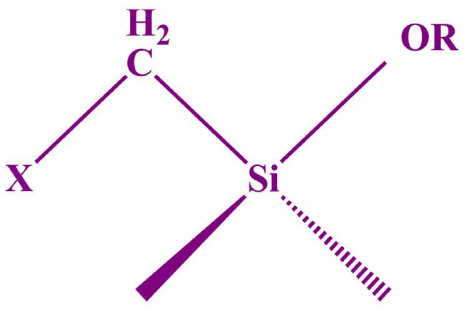

$\alpha$-alkoxysilane

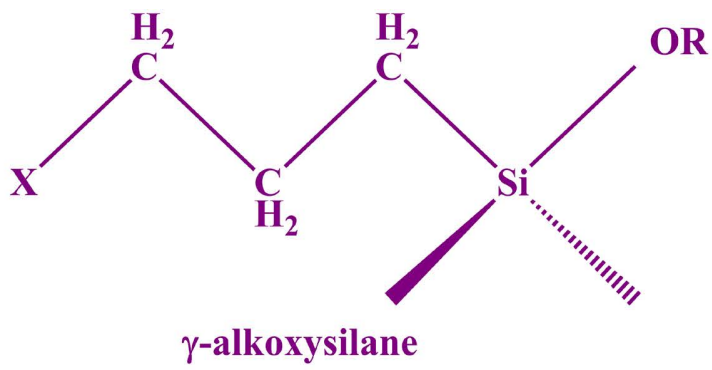

Figure 3. $\alpha$ - and $\gamma$-alkoxysilanes in organofunctional alkoxysilanes. 
more extensively by forming three-dimensional siloxane networks and interconnecting with the functional silanes. Thus, a rigid siloxane network is formed and as a result, more energy is required to break apart the cross-linking network. Furthermore, the penetration of water molecules into the inner interfacial layer becomes more and more difficult as the degree of the cross-linking siloxane network increases [5] [6].

\section{Silane Coupling Agents}

Silane coupling agents can form a durable bond between organic and inorganic materials. Interfaces involving such materials have become a dynamic area of chemistry in which surfaces have been modified to generate desired heterogeneous environments or to incorporate the bulk properties of different phases into a uniform composite structure [8]. Coupling agent formula is shown in Figure 4. Coupling age nts bind organic polymers to fillers such as fiberglass/silica or mineral fillers like talc, mica, clay, and wollastonite. Silane as a coupling agent, silanes help to improve bonding and mixing as well as to increase the matrix strength between these polymers and fillers [6].

The general formula for a silane coupling agent typically shows the two classes of functionality. $\mathrm{X}$ is a hydrolysable group typically alkoxy, acyloxy, halogen or amine. The $\mathrm{R}$ group is a nonhydrolyzable organic radical that may possess a functionality that imparts desired characteristics.

\section{Silane Terminated Polyurethane}

In 2004 O'Connor et al. [12] were the first to review the synthesis methods and development of silyl-terminated polyurethanes for construction applications. The use of organofunctional silanes as crosslinking units for polyurethanes was first reported in the early 1970s by a patent by $3 \mathrm{M}$ [13]. Brode and Conte [14] followed shortly and synthesized SPUR prepolymer with different aliphatic and mercapto silanes. In the early 1980's Berger et al. [15] improved this new technology by using secondary amino bis-silanes which significantly improved the properties of the adhesives, sealants, and coatings with respect to flexibility and curing times.

In the first step a conventional polyurethane prepolymer is formed by reaction of a polyol with an excess amount of a diisocyanate. The free isocyanate groups are then end-capped with compounds containing reactive alkoxysilane groups. After application the alkoxysilane end groups undergo hydrolysis and condensation reactions in the presence of moisture giving the cured prepolymers desired.

\section{Organof unctional group}

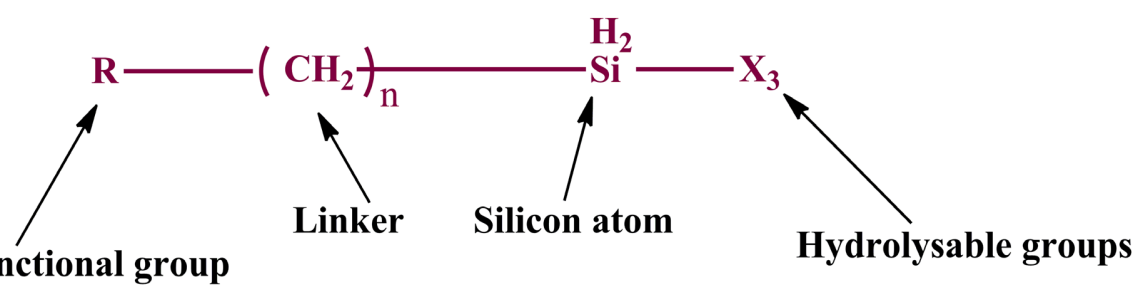

Figure 4. Formula for a silane coupling agent. 
In 2006, Xu et al. [16] reported the synthesis and shape memory effects of $\mathrm{Si}-\mathrm{O}-\mathrm{Si}$ cross-linked hybrid polyurethanes. The first step is the synthesis of a silane end-capper by Michael addition of aminosilane and acrylate. In the second step a diisocyanate and polyol compound are reacted to give the polyurethane backbone having free isocyanate groups. In the third step the isocyanate-terminated polyurethane reacts with the silane end-capper and results in the inorganic-organic hybrid material. The same synthesis strategy was applied by Nomura et al. in 2007 [17] and is shown in Figure 5.

Subramani et al. [18] [19] [20] used a slightly different route to prepare the SPUR desired. A polyol is reacted with a dimethylol propionic acid (DMPA) and a diisocyanate in the first step. The free isocyanate groups of the polyurethane are then end-capped with an amino alkoxysilane. Furthermore, acetone is added in order to reduce the viscosity of the polymer and triethylamine to neutralize the $\mathrm{COOH}$ groups. Sardon et al. [21] used the same reaction pathway by using acetone as solvent of the reaction. After functionalization of the polyurethane with an aminoalkoxysilane the emulsification process is started by the addition of water, and acetone is removed by distillation. The reaction scheme of this synthetic route is shown in Fig ure 6.

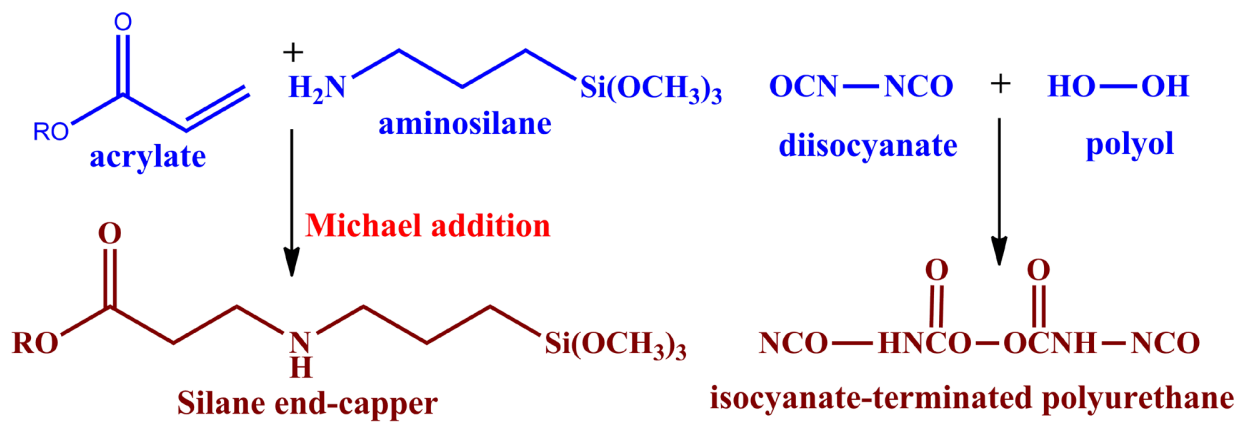

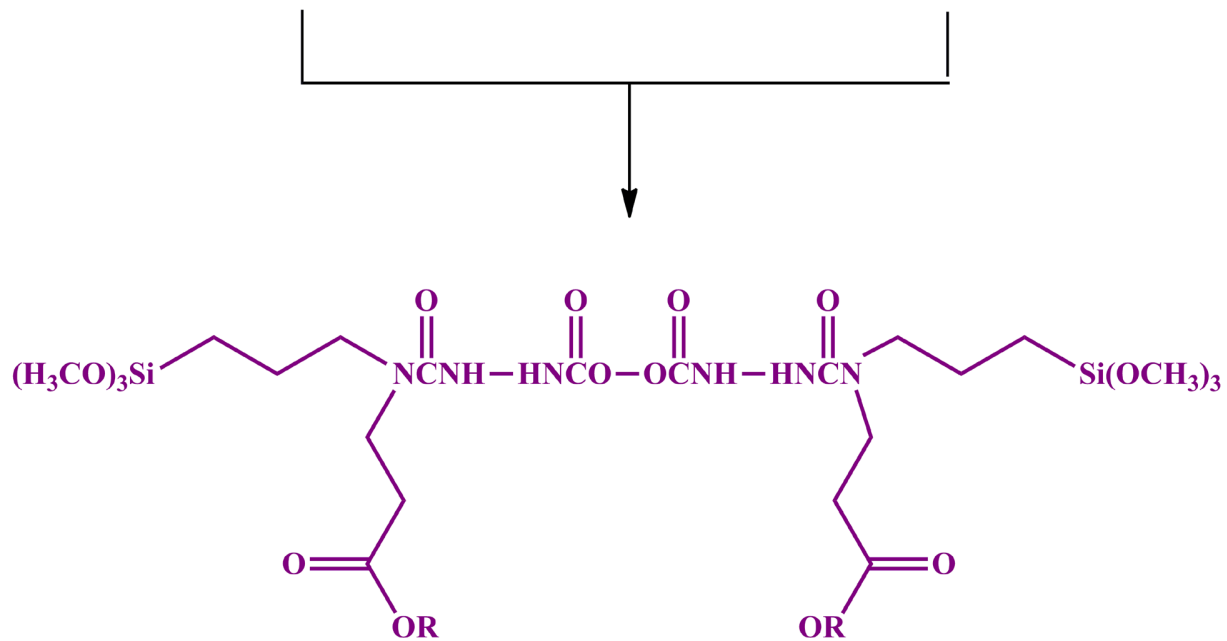

silyl-terminated polyurethane

Figure 5. Synthesis pathway for SPUR's. 
Triethoxysilane and linseed polyol as inorganic and organic precursors were used by Akram et al. [22]. This so-called Si/linseed polyol is further treated with a diisocyanate to give organic-inorganic hybrid polyurethane composites. Vega-Baudrit et al. [23] investigated the properties of thermoplastic polyurethanes by agglomeration of nano silica particles within a polyurethane matrix. The thermoplastic polyurethane is prepared by the standard prepolymer method and mixed with the nano silica in 2-butanone.

\subsection{Steps of Silane Terminated Polyurethane Synthesis}

\subsubsection{Polyurethane Formation}

The network formation process of diol-diisocyanate systems catalyzed by dibutyltin dilaurate was investigated by Dusek et al. [24] in 1990. The most important reactions that occur are summarized in Fig ure 7. They claim that the molar

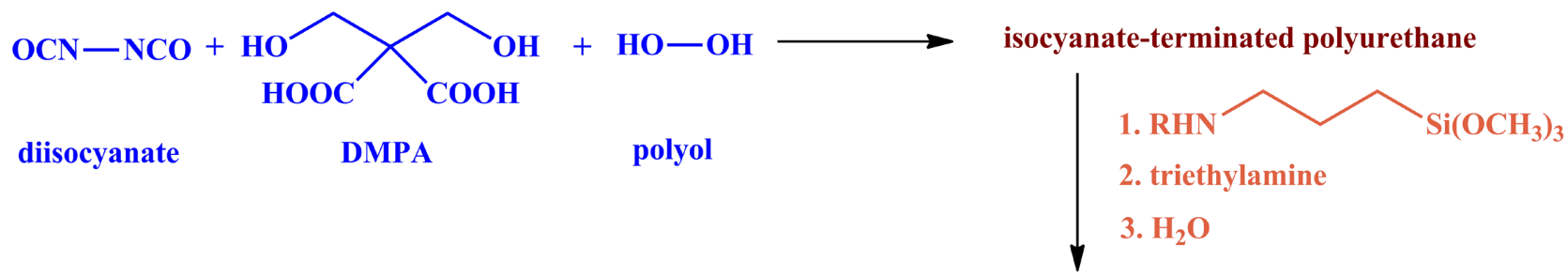

silyl-terminated polyurethane

Figure 6. Synthesis of STPUs [21].

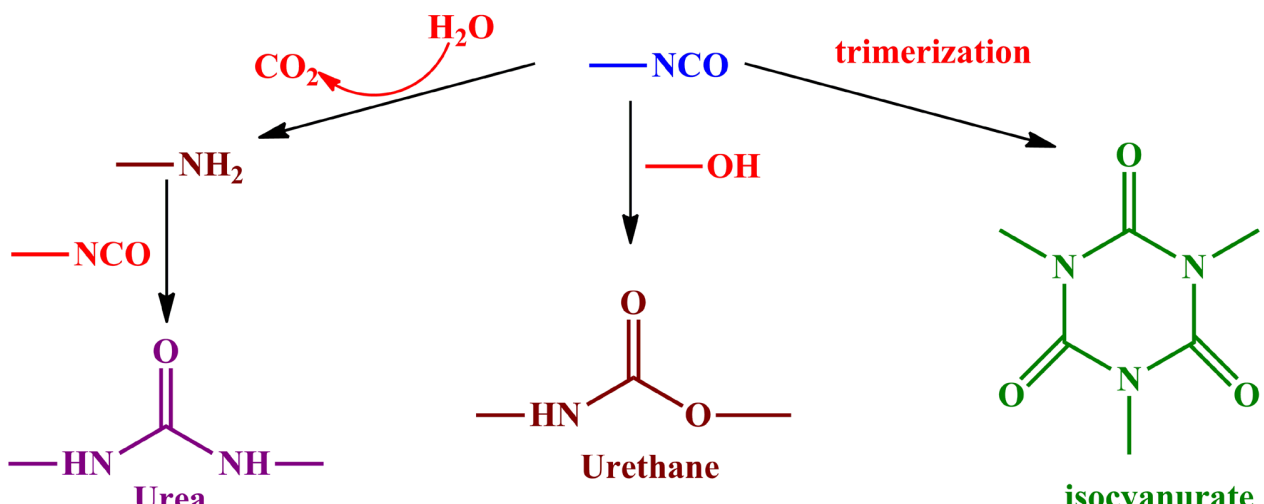<smiles>CNC(=O)CNC(=O)N(C)C(=O)NC</smiles>

biuret<smiles>CNC(=O)N(C)C(=O)OC</smiles>

Figure 7. Isocyanate side reactions. 
ratio $\mathrm{OH} / \mathrm{NCO}$ has an impact on the importance of the side reactions. Side reactions cannot be inhibited if isocyanate is in excess. However, at lower temperatures $\left(\leq 60^{\circ} \mathrm{C}\right)$ the formation of biuret and allophanate is very slow.

\subsubsection{End-Capping}

The end-capping reaction is done with di- or tri-functional amino silanes [25] [26]. The amino groups are reacted with the free isocyanates to give stable urea groups. A tri-functional silane having three methoxy or ethoxy groups induces higher cross linking and faster cure. Methoxy silanes as end-cappers also lead to faster cure rates than those of ethoxy silanes [27].

Isocyanate functional silanes couple with the polyol. Alkanolamine functional silanes react with the isocyanate to form urethane linkages, while amine silanes react with the isocyanates to yield urea linkages as shown in Figure 8 [28].

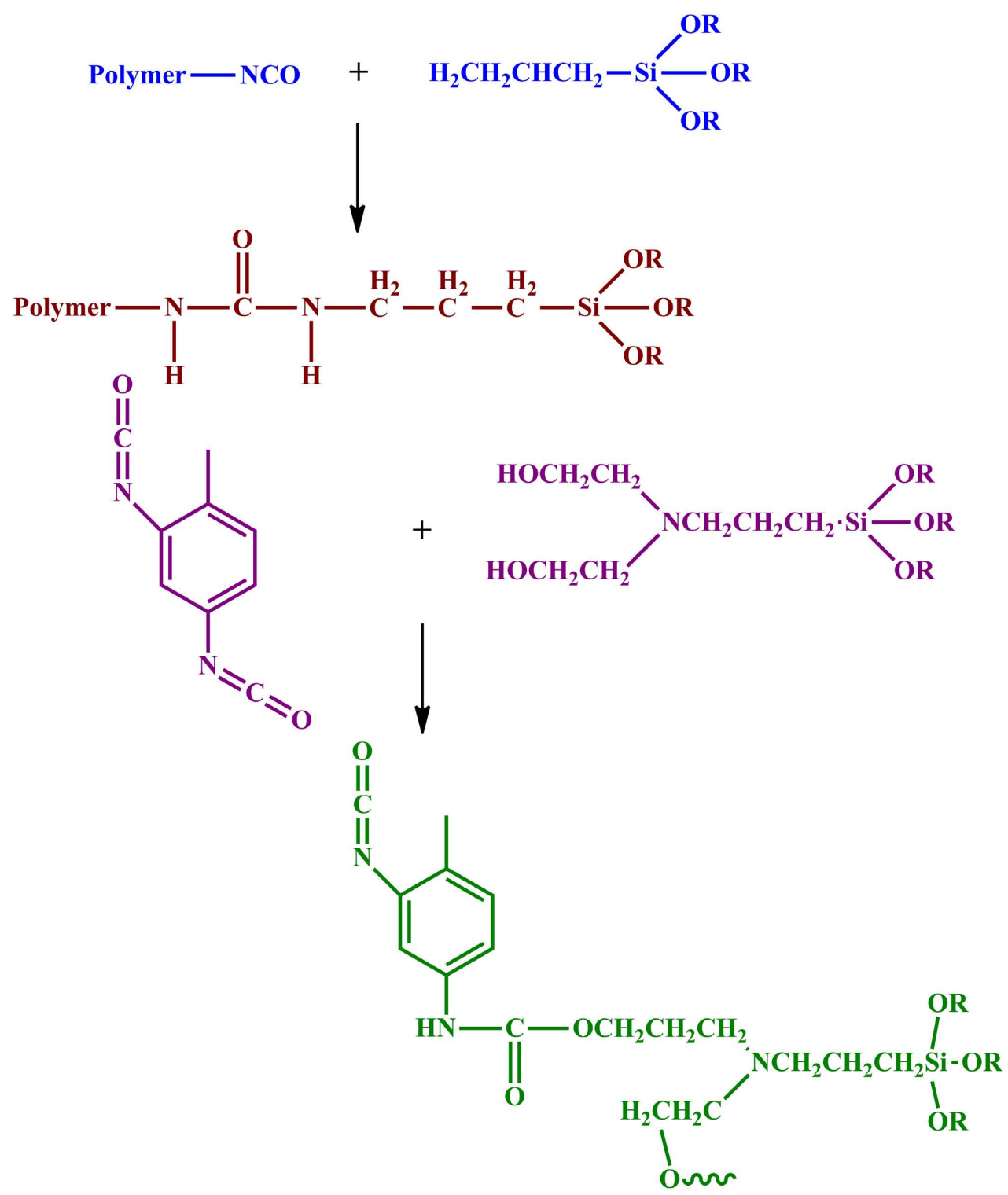

Figure 8. Polyurethane coupling reaction. 
Secondary a mino sila nes have the general ability to convert isocyanate functional urethane prepolymers to systems that crosslink in the presence of water and a tin catalyst as shown in Figure 9. The preferred amino silanes are secondary containing methyl, ethyl or butyl substitutions on nitrogen.

From an industrial viewpoint, much attention has been paid to one-component, solvent-free urethane elastic adhesives based on the isocyanate-terminated polyurethanes. However, these Isocyanate-terminated polyurethanes have several drawbacks, such as a slow curing speed, a low bonding strength due to foaming by carbon dioxide generated by the reaction of isocyanate groups with water, and toxicity of the isocyanate groups. These inadequacies motivated led to develop alkoxy silyl compounds with amino groups, which can be used as end-capping silane age nts to modify the isocyanate groups of polyurethanes as shown in Figure 10.

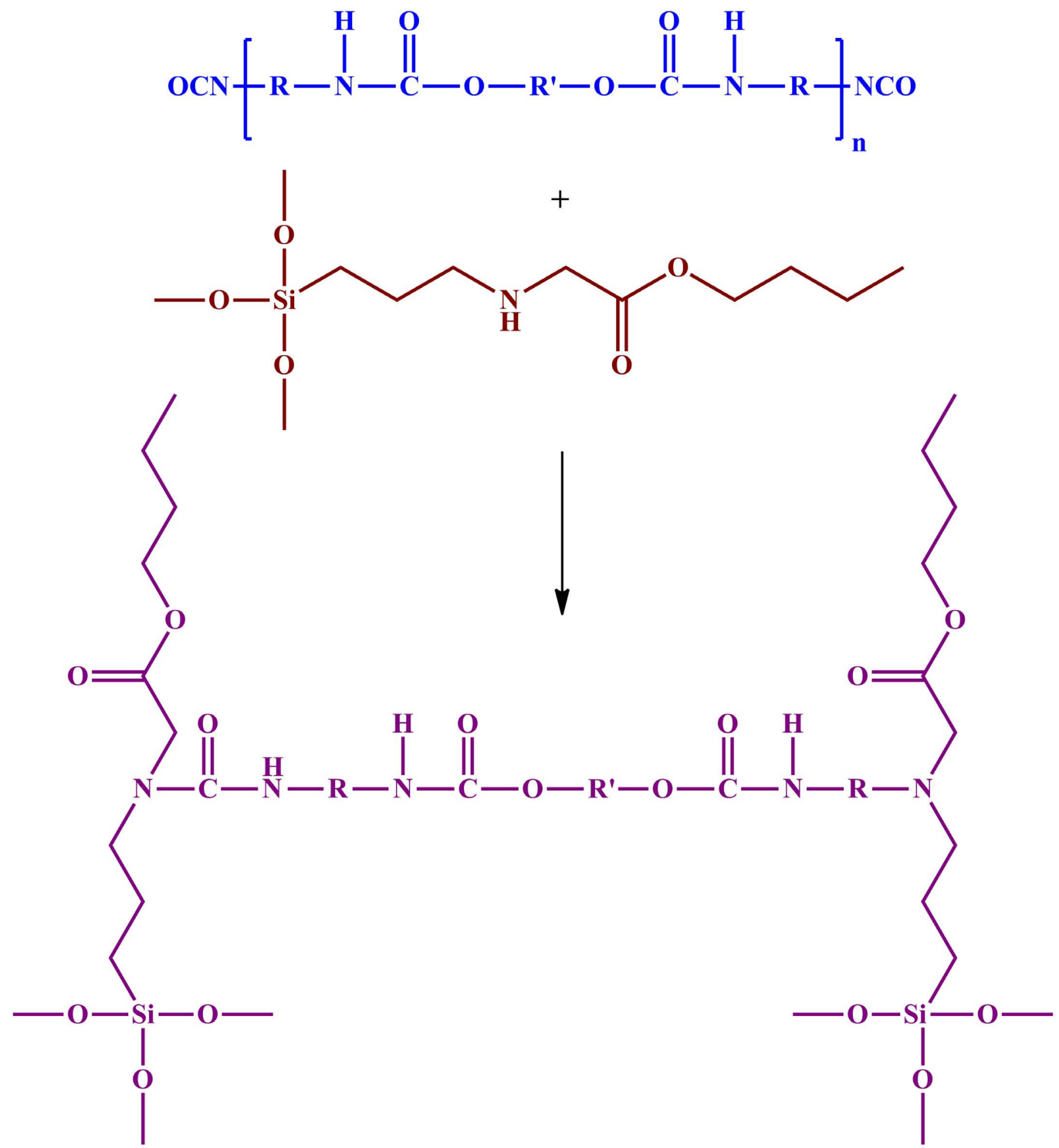

Figure 9. Moisture curable silylated polyurethane. 


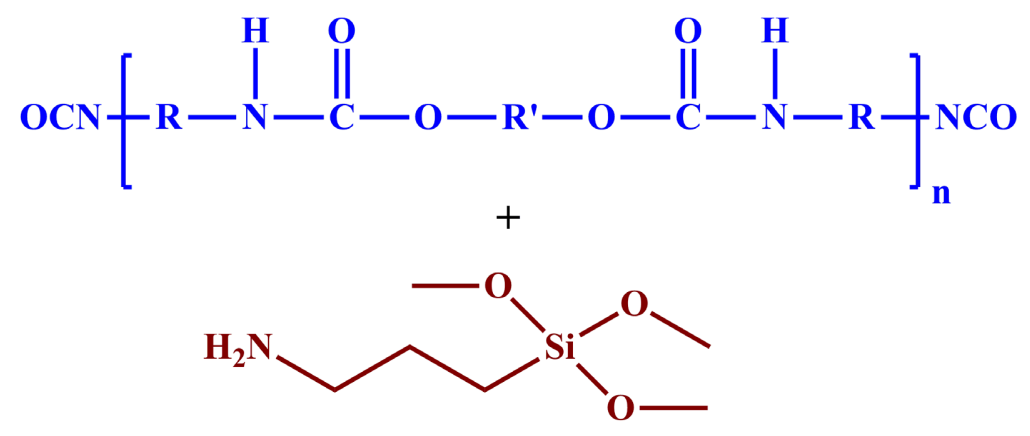

3-AMINOPROPYLTRIMETHOXYSILANE

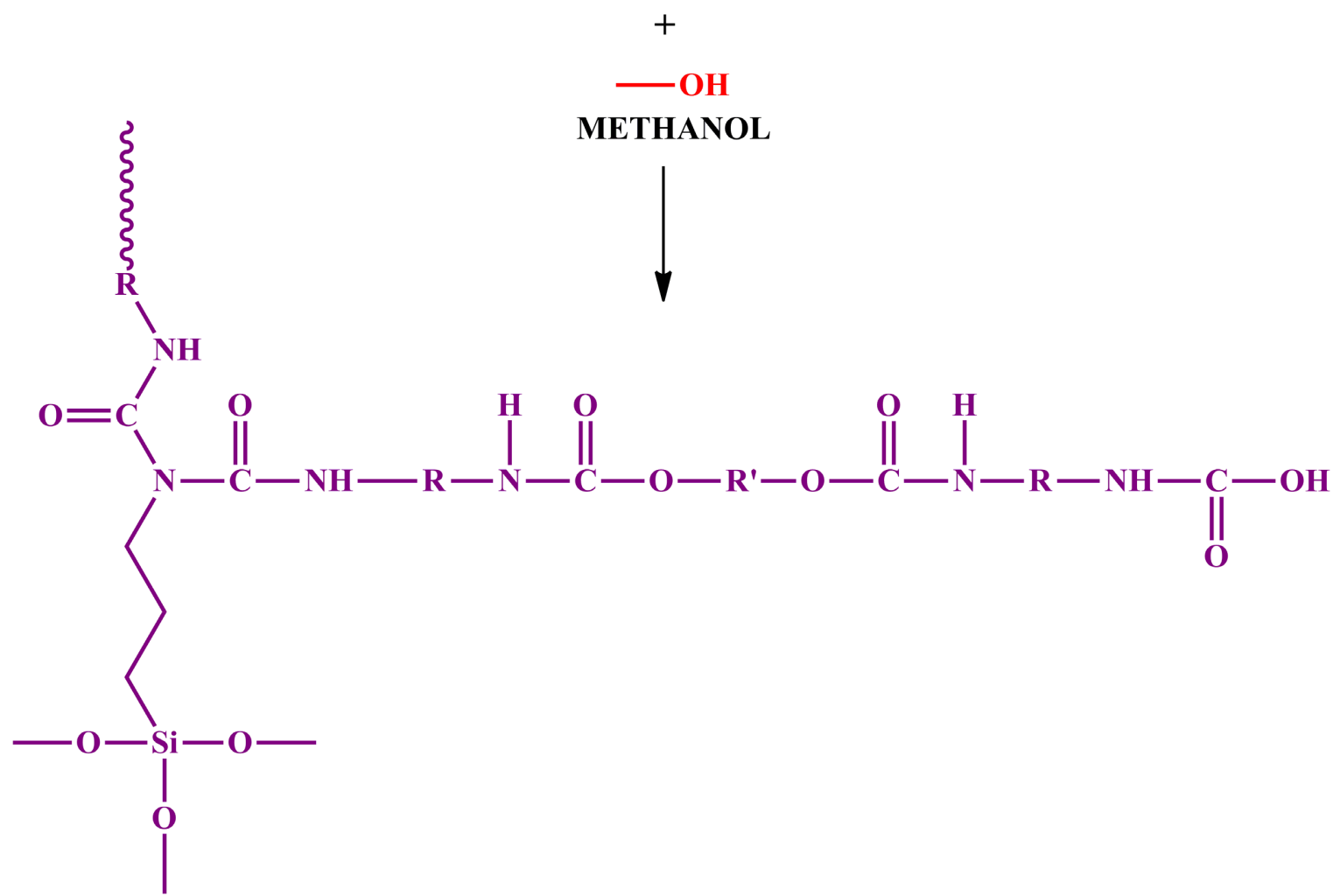

Figure 10. Reaction of isocyanate terminated Polyurethane prepolymer with primary amino silane and an active hydrogen compound.

Michael addition is known as a process in which an amino group reacts quantitatively with an $\alpha, \beta$-unsaturated carbonyl group under mild conditions. The Michael addition technology was applied to synthesize novel silane end cappers by the reaction of a commercial primary amino silane (3-amino propyl trimethoxy silane) and a variety of acrylates. The resulting trialkoxysilane compound having mainly secondary amine groups could be successfully used as an end-capping agent for the terminal isocyanate groups of conventional polyurethanes. The physical properties, the curing speed, the tensile shear bond strength, and the adherence were found to be controlled by the structures of the silane end cappers, the main chain of the polyurethane, and the composition of the silane end cap- 
per and the isocyanate-terminated polyurethane in the feed [29] [30] [31] [32] [33].

As the silane-end capping agents are costly. Wang and their team members [34], two silane-terminated Polyurethane prepolymer were synthesized by end capping with $\gamma$-amino propyl trimethoxy silane (APTMS). First Silylated prepolymer was partially end capped with APTMS, while free NCO groups are free and Second Silylated prepolymer was end capped partially with APTMS and partially with active hydrogen compounds which has an inert group attached to it such as Methanol. Both pre-polymers were formulated with same formulations and second silyated polyurethane pre-polymer shows better mechanical properties [34] [35]. Silylated polyurethane obtainable by Ralf Baetzgen and their team members comprising the following steps as shown in Figure 11 [36].

The silylated Polyurethane are suitable for use in a preparation as an adhesive, sealants, or a coating agent. Modified-silane adhesives and sealants have a polyether backbone and the reactive terminal and Crosslinkable terminal groups are alkoxy groups. These hybrid Polyurethanes have the advantages of being free from terminal isocyanates groups [37] [38] [39].<smiles>[R][C@](C)(O)OC(=O)NN[R]([H])(C)O</smiles><smiles>[R]O[Si]([R])([R20])CCCN=C=O</smiles>

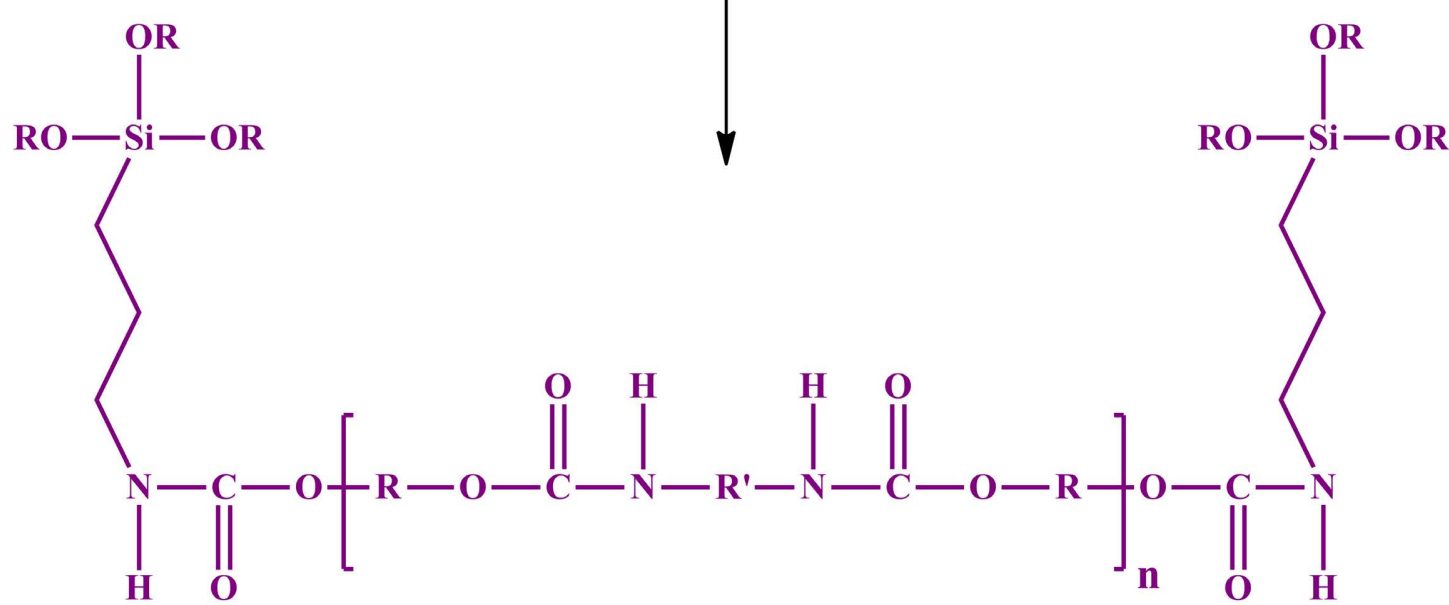

Figure 11. Synthesis of SPUR using isocyanate silanes. 


\section{Silane Terminated Polyethers}

All commercially available silane modified polymers contain alkoxy silyl groups and are thus able to crosslink in the presence of moisture [40]. They differ in their organic structure, notably the manner the silyl groups are linked to the polymer backbone and the distance between the silyl groups and the backbone. In the case of silane-terminated polyethers, the silyl groups are coupled to the ends of the polyether backbone via an alkylene unit and a urethane group. The alkylene unit can either be a methylene group, in which case it is a silane terminated polyether, or a propyle ne group, in which case it is a silane terminated polyether. The length of the alkylene unit in-fluences the reactivity of the alkoxysilylations of silane-terminated polyethers cure rapidly without needing a tin catalyst; the presence of a catalytic primary amino compound will suffice to kick off the catalytic reaction.

\subsection{Silane Terminated Prepolymers-Chemistry}

$\alpha$-silane-terminated polyether is used as resin, the fully cured adhesive offers a combination of strength and elasticity that is ideal for various applications. The $\alpha$-effect makes the innovative resin highly reactive. The setting speed can be adjusted by the choice of catalyst system, and even tin-free catalyst systems are possible. The high reactivity characteristic of $\alpha$-silanes is retained even when they are attached to organic polymers. $\alpha$-silane terminated polymers always crosslink very quickly. Figure 12 and Figure 13 illus trates $\alpha$ and $\gamma$ silane terminated prepolymers.

Even dimethoxysilyl and triethoxysilyl end groups are more reactive in $\alpha$-silaneterminated polyethers than the trimethoxysilyl end groups of $\gamma$-silane-terminated polyethers. Difunctional silanes have the advantage that they release less methanol during the crosslinking process. In addition, a lower crosslinking density is obtained with them than with trifunctional silanes, thus favoring the formation of a more elastic vulcanizate. Alkoxysilanes with an $\alpha$-terminal isocyanate group have proven particularly useful in reacting with organic polymers as shown in Figure 12. There are three reasons for this: first, the isocyanate group $(-\mathrm{N}=\mathrm{C}=\mathrm{O})$ permits bonding to various orga nic base polymers. Second, the bonding reaction is easy to control, and third, the reaction is quantitative. In the resulting $\alpha$-silaneterminated polymer, the terminal silyl groups are irreversibly joined to the polymer chain via a stable urethane bond; the product contains no free isocyanate groups [41].

\subsection{Fast Curing Technology}

Chemical modification of the silane functional group is another tool to improve the properties of the silane-terminated polyether's. The current market trend requires adhesives with very fast strength development and faster curing. Drawback of these systems is however that most of these adhesive's lack in elongation or elasticity. The first generation of MS Polymer with the dimethoxy-methyl silyl 

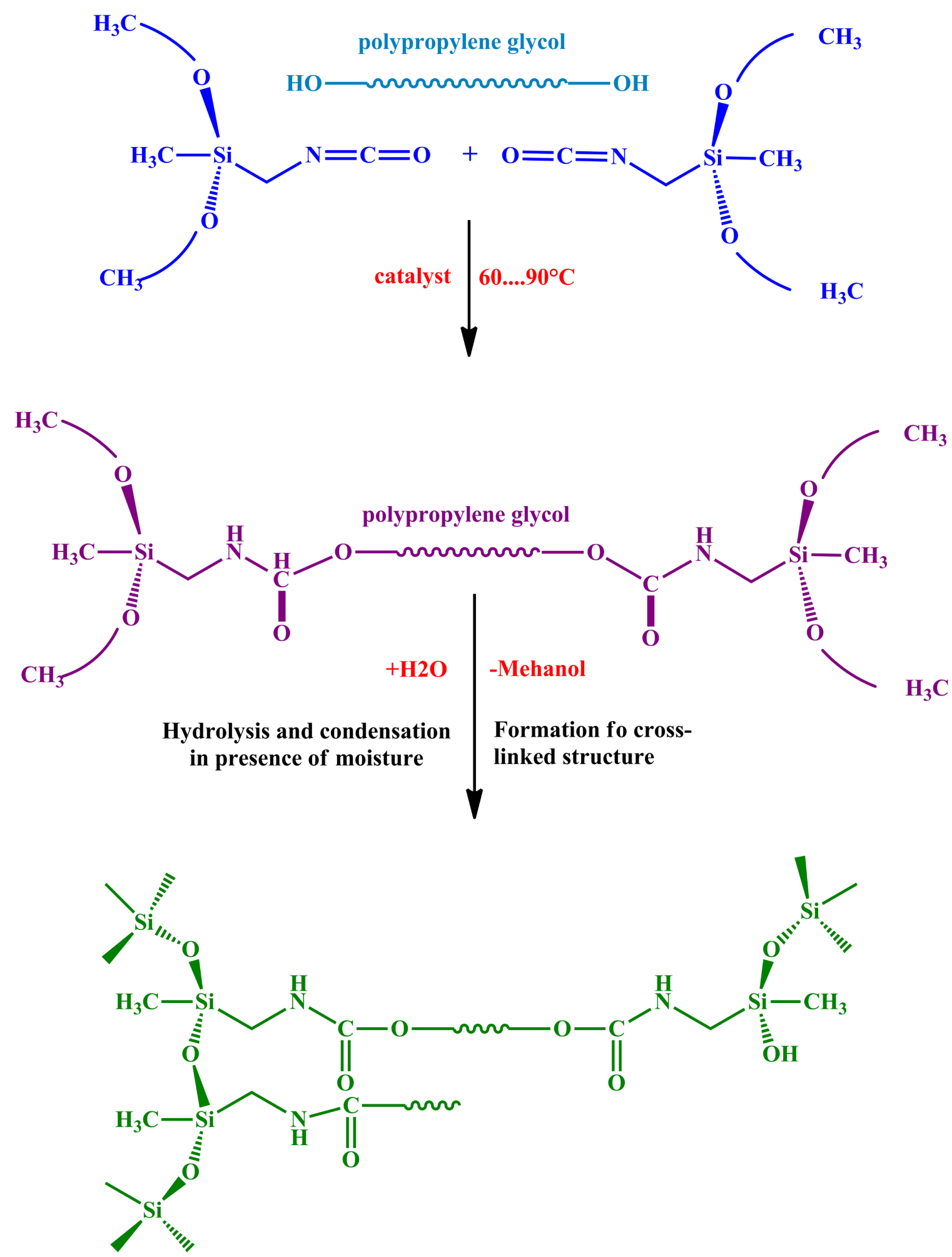

Figure 12. Synthesis of a silane terminated prepolymers.

end groups has an excellent elastic behavior but is relatively low in reactivity. Faster curing systems were later developed by replacing the dimethoxymethyl silyl group with trimethoxysilyl groups, as consequence that elongation dropped, 
<smiles>CCCCCOC(=O)NC[Si@](C)(OCC)OC[C@H](C)OC(=O)NC[Sn](C)(OC)OC</smiles><smiles>CCCCCOC(=O)NCCC[Si](OC)(OC)OCCCCNC(=O)OCCC[Si](OC)(OC)OC</smiles>

Figure 13. $\alpha$ and $\gamma$ silane terminated prepolymers.

certainly with the silylated-ed polyurethane types. The next step was the development of very fast curing systems, such as the $\alpha$-type MS polymer, which keeps the inherent low elongation, resulting in more brittle products.

\subsection{High Strength Technology}

The second-generation MS Polymer modified with polyacrylate can control the morphology. By redesigning of the backbone and polymer structure, glass transition temperature $(\mathrm{Tg})$ of the polymer can be controlled and consequently the compatibility of the polymers before and after curing can be manipulated. Acrylic domains are formed in a polyether matrix and these acrylic domains enhance the strength significantly. Moreover, the acrylic domains will provide an improved adhesion to plastic substrates.

\section{Curing Mechanism: MS \& SPUR Adhesives, Sealants, and Coatings}

The silane groups provide a non-isocyanate curing mechanism, better adhesion to various substrates, and excellent storage stability. These reactive end-groups cures in the presence of moisture in the atmosphere and an appropriate catalyst by means of an alkoxy reaction that is different than the conventional silicone cure mechanism. The water reacts with the silane group to produce silanol. Further reaction of the silanol with either another silanol or methoxysilane produces three- 
dimensional siloxane linkages. The crosslinking reaction proceeds in two steps illustrated in the Figure 14 and Figure 15 below.

Step 1:

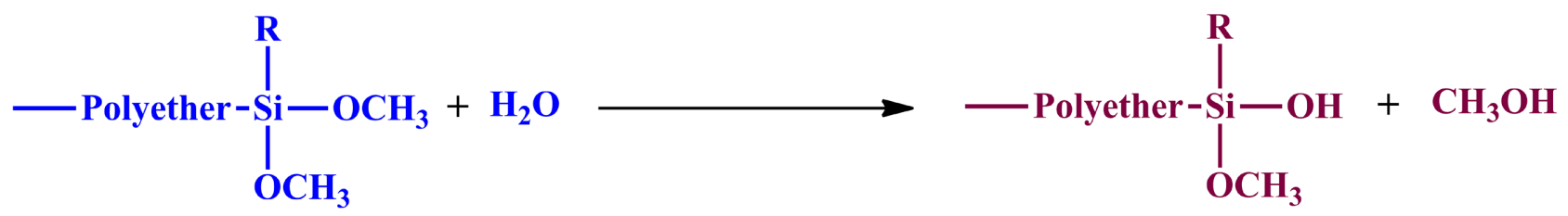

Figure 14. Conversion from methoxysilane to silanol.

Step 2:

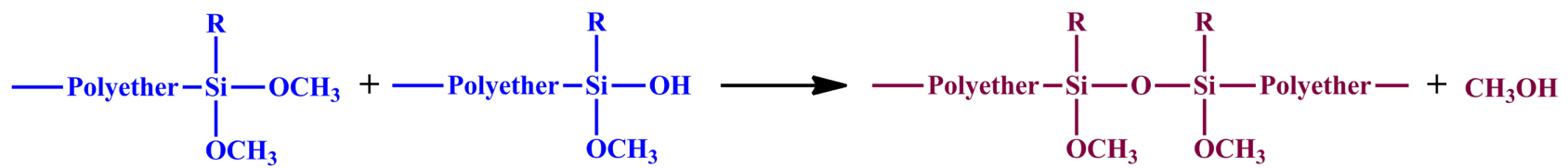

Figure 15. Condensation of silanol groups to form siloxane crosslink.

To make the curing mechanism happen, both water (e.g., ambient moisture) and a catalyst are required.

\section{Key Properties and Performance of MS and SPUR}

1) Health and Safety during Formulation and Application: Perhaps the most compelling value proposition associated with MS Polymer adhesives, sealants and coatings are their lack of free isocyanates and solvents. Their absence broadens the range of formulation possibilities and allows the end product to meet stringent environmental regulations.

2) Lack of I socyanates: The silyl-terminated polymer eliminates the need for isocyanate. Isocyanates are highly reactive chemicals. Consequently, formulations containing isocyanates must be protected from contact with reactive agents, including moisture, as this will drastically decrease shelf life. Isocyanates are also considered to be hazardous materials to use. Since no isocyanates are present, bubbling during curing is not a concern as it often is with polyurethane systems. Bubbles can damage the integrity of the sealant or adhesive. MS Polymer sealants do no bubble on the surface at all. The sealants and coatings surface is kept smooth and intact.

3) Lack of Solvents: The low viscosity of Silane terminated prepolymers allows for a solvent-free formulation that is less dependent on temperature change. Therefore, formulations are easy to process and have low temperature gunnability. The absence of solvent provides environmentally friendly sealants that meet environmental regulations regarding volatile organic contents (VOCs), out-gassing, and toxicity. Furthermore, the lack of solvents protects the formulator from the rising cost of solvent raw materials and VOC mitigating facilities.

4) Applications: One-part Silane terminated prepolymers based adhesives, 
sealants and coatings cure relatively fast even at low temperatures. Thus, they find use in applications where property development speed is important Once cured, Sila ne terminated prepolymers based adhesives, sealants and coatings also exhibit little dirt pick up when compared to silicone-based systems.

5) Performance during Service: The rise in Silane terminated prepolymers based adhesives, sealants and coatings popularity has been primarily due to its versatility and well-balanced properties [42].

Compared with the other two types of sealants, Silane terminated prepolymers based adhesives, sealants and coatings have well balanced properties and performance. Some of the unique properties of Silane termi nated prepolymers are:

- Environmental friendliness (solvent free and -NCO free)

- Low temperature gun nability and flowability

- Silane terminated prepolymers based sealants do not stain as some silicone sealants do because of low molecular weight silicon materials that bleed from the surface of sealed joints.

- Silane terminated prepolymers adhesives, sealants and coatings provide good paintability unlike silicone sealants.

- Silane terminated prepolymers shows no cracking, splitting, discoloration or adhesion failure after seven years of testing in desert climate.

- Silane terminated prepolymers based adhesives, sealants and coatings provide adhesion to various substrates including metals, plastics, wood, and ceramics.

- Shelf life is excellent although must be protected from moisture.

Performance Comparison of Silane terminated prepolymers, Polyurethane, and Silicone based Sealants is shown in Table 2.

\section{Applications of Silane Terminated Prepolymers}

Adhesives, sealants and coatings, as they are used in many fields, require a series of different properties for unique function. Costumers are looking for high-performance construction adhesives and sealants useful for a various type of applications. In modern construction, water-based and solvent-free systems are dominating due to their low toxicity with regard to the environment [44] [45]. These types of adhesives and sealants avoid strong curing shrinkage, which typically appears in solvent-based systems, and, additionally, the liberation of volatile compounds is reduced. Polyurethanes have grown commercially as adhesives, seala nts and coatings as they have excellent adhesion to a wide range of materials, perfect abrasion resistance, good flexibility and hardness. These properties make them useful for products such as coatings, adhesives and sealants. So-called Silyl-Terminated Polyurethanes (STPU) combine the advantages of polyurethane and silicone sealants [46].

That's why such cases call for low-modulus elastic hybrid sealants that require only a little force to stretch or compress. When the strain is removed, they largely return to their original form. These types of sealants absorb the components' move- 
ments and thus lessen the strain on the joint edges. In practice, a sealant may also be required to bond the two substrates together. Experts refer to this as an adhesive sealant or elastic adhesive. While such an allrounder should be capable of transferring forces, it should also be elastic, so that it can accommodate the component's movement. This is the case for assembly adhesives, for example, which should be strong yet elastic [47]. There are many applications in which the bonded joint must be not only strong but also elastic. Elasticity becomes more important as soon as the bonded joint is subjected to a dynamic load. Since elastic adhesives deform reversibly and can absorb dynamic loads in the process, they have become firmly established in many applications. It would be unthinkable today to assemble the bodywork of buses, railroad cars, campers, mobile homes and refrigerated trucks, for example, without elastic adhesives. Elastic adhesives are also becoming increasingly common in aircraft construction and shipbuilding. The binders used in elastic adhesives derive mainly from two polymer classes, namely polyurethanes (PUR) and silane terminated polymers. Polyurethanes crosslink using isocyanate chemistry. Silane-terminated prepolymers crosslink via the alkoxysilane units attached to the ends of the polymer chain. These polymers form highly stable silicon-oxygen-silicon bo nds when they cure, which is typical of silicones. Aside from undeniable advantages, all the commercially available binders suitable for formulating elastic adhesives also have some specific disadvantages. Polyurethane systems, for example, cure to produce materials with very high tensile strengths. However, in terms of their elongation at break and adhesion to various substrates (without pretreatment), they are inferior to the vulcanizates of adhesives formulated with silane-terminated polyethers. Silane-terminated polyurethanes, which could be described as a combination of the two systems, are either not very easy to compound because of their high viscosity [48].

\section{Futuristic Developments}

The advantages arising from new molecular design for the silylated polymer were improved elastic recovery and better through cure, even in deep layers or for bonding of large surface areas. Moreover, improved adhesion to a very wide variety of substrates was achieved by adaptation of the polymer backbone, for example by adjusting its polarity and crystallinity. These properties allowed the use of polymers in applications that were previously addressed only with difficulty [49].

\section{Conclusion}

Combining different polymer chemistries to develop new products can be challenging, but the potential benefits of success are making this a hot topic in the adhesives, sealants and coatings industries. Silylated prepolymers a re considered to be "hybrid" molecules because they provide the best properties of polyurethane and silicone while limiting their inherent weaknesses. In addition to their unique 
performance and application properties, these polymers have achieved widespread acceptance due to their solvent-free and isocyanate-free nature. Here, we discussed the chemistry, advantages and disadvantages of Silylated prepolymersbased adhesives, sealants and coatings and provides information on different end applications. In order to cope with the current and future market requirements, the new generation of silane-terminated polymer technologies has greater importance in terms of final applications like low viscous reactive diluents, non-yellowing polyacrylate modified high strength polymers and fast curing elastic polymers. Comparisons to conventional silicones, polyurethanes and acrylic demonstrate that Silylated prepolymers-based products offer excellent properties for applications requiring long-term exposure to chemicals. Since its introduction, additional development work in health care, aerospace, automotive and electronic applications has continued.

\section{Conflicts of Interest}

The authors declare no conflicts of interest regarding the publication of this paper.

\section{References}

[1] Petrie, E.M. (2009) Silyl Terminated Construction Sealants. SpecialChem.

[2] Bichler, K. and Zander, L. (2012) Innovative Hybrid Polymers for High-Strength Adhesives. Adhesion Adhesives \& Sealants, 9, 24-28. https://doi.org/10.1365/s35784-012-0062-4

[3] Feng, T.M. and Waldman, B.A. (1995) Silylated Urethane Polymers Enhance Properties of Construction Sealants. Adhesives Age, 30-32.

[4] Witucki, G.L. (1993) A Silane Primer: Chemistry and Applications of AIkoxy Silanes. Journal of Coatings Technology, 65, 57-60.

[5] Matinlinna, J.P., Lung, C.Y.K. and Tsoi, J.K.H. (2018) Silane Adhesion Mechanism in Dental Applications and Surface Treatments: A Review. Dental Materials, 34, 13-28. https://doi.org/10.1016/j.dental.2017.09.002

[6] Plueddemann, E.P. (1983) Silane Adhesion Promoters in Coatings. Progress in Organic Coatings, 11, 297-308. https://doi.org/10.1016/0033-0655(83)80012-0

[7] Arkles, B. (2015) Silane Coupling Agents Connecting across Boundaries. Gelest Inc., Morrisville, PA.

[8] Osterholtz, F.D. and Pohl, E.R. (1992) Kinetics of the Hydrolysis and Condensation of Organofunctional Alkoxysilanes: A Review. Journal of Adhesion Science and Technology, 6, 127-149. https://doi.org/10.1163/156856192X00106

[9] Ying, C., Lung, K. and Matinlinna, J.P. (2012) Aspects of Silane Coupling Agents and Surface Conditioning in Dentistry: An Overview. Dental Materials, 28, 467-477. https://doi.org/10.1016/j.dental.2012.02.009

[10] Arkles, B., Steinmetz, J.R., Zazyczny, J. and Mehta, P. (1992) Factors Contributing to the Stability of Alkoxysilanes in Aqueous Solution. Journal of Adhesion Science and Technology, 6, 193-206. https://doi.org/10.1163/156856192X00133

[11] Zhang, X.Q., Yue, W., You, Y.P. and Luo, S. (2011) Silane Treatment Technology on Alumin um Surface. Advanced Materials Research, 239-242, 2687-2693. https://doi.org/10.4028/www.scientific.net/AMR.239-242.2687 
[12] Khatoon, H., Iqbal, S., Irfan, M., Darda, A. and Rawat, N.K. (2021) A Review on the Production, Properties and Applications of Non-Isocyanate Polyurethane: A Greener Perspective. Progress in Organic Coatings, 154, Article ID: 106124. https://doi.org/10.1016/j.porgcoat.2020.106124

[13] Zanetti, M., Marini, D., Pasqualini, E., Masetto, E. and Cavalli, R. (2015) Hybrid Silane-Crosslinking Polymers: A Potential Alternative to Polyurethane Wood Adhesives? A Preliminary Investigation by TMA. European Journal of Wood and Wood Products, 74, 127-130. https://doi.org/10.1007/s00107-015-0988-8

[14] Gadhave, R., Sheety, P., Mahanwar, P., Gadekar, P. and Desai, B. (2019) Silane Modification of Starch-Based Wood Adhesive: Review. Open Journal of Polymer Chemistry, 9, 53-62. https://doi.org/10.4236/ojpchem.2019.93005

[15] Berger, M., Mayer, W. and Ward, R. (1983) Silane-Containing Isocyanate-Terminated Polyurethane Polymers. US Patent, US4374237A.

[16] Xu, J., Shi, W. and Pang, W. (2006) Synthesis and Shape Memory Effects of Si-O-Si Cross-Linked Hybrid Polyurethanes. Polymer, 47, 457-465. https://doi.org/10.1016/j.polymer.2005.11.035

[17] Nomura, Y., Sato, A., Sato, S., Mori, H. and Endo, T. (2007) Synthesis of Novel Moisture-Curable Polyurethanes End-Capped with Trialkoxysilane and Their Application to One-Component Adhesives. Journal of Polymer Science Part A: Polymer Chemistry, 45, 2689-2704. https://doi.org/10.1002/pola.22025

[18] Subramani, S., Lee, J.M., Lee, J.Y. and Kim, J.H. (2007) Synthesis and Properties of Room Temperature Curable Trimethoxysilane-Terminated Polyurethane and Their Dispersions. Polymers for Advanced Technologies, 18, 601-609. https://doi.org/10.1002/pat.860

[19] Subramani, S., Choi, S.W., Lee, J.Y. and Kim, J.H. (2007) Aqueous Dispersion of Novel Silylated (Polyurethane-Acrylic Hybrid/Clay) Nanocomposite. Polymer, 48, 4691-4703. https://doi.org/10.1016/j.polymer.2007.06.023

[20] Subramani, S., Lee, J.Y., Kim, J.H. and Cheong, I.W. (2007) Crosslinked Aqueous Dispersion of Silylated Poly (Urethane-Urea)/Clay Nanocomposites. Composites Science and Technology, 67, 1561-1573. https://doi.org/10.1016/j.compscitech.2006.07.011

[21] Sardon, H., Irusta, L., Fernández-Berridi, M.J., Lansalot, M. and Bourgeat-Lami, E. (2010) Synthesis of Room Temperature Self-Curable Waterborne Hybrid Polyurethanes Functionalized with (3-Aminopropyl) Triethoxysilane (APTES). Polymer, 51, 5051-5057. https://doi.org/10.1016/j.polymer.2010.08.035

[22] Akram, D., Ahmad, S., Sharmin, E. and Ahmad, S. (2010) Silica Reinforced Organic-Inorganic Hybrid Polyurethane Nanocomposites from Sustainable Resource. Macromolecular Chemistry and Physics, 211, 412-419. https://doi.org/10.1002/macp.200900404

[23] Vega-Baudrit, J., Sibaja-Ballestero, M., Vázquez, P., Torregrosa-Maciá, R. and MartínMartínez, J.M. (2007) Properties of Thermoplastic Polyurethane Adhesives Containing Nanosilicas with Different Specific Surface Area and Silanol Content. International Journal of Adhesion and Adhesives, 27, 469-479. https://doi.org/10.1016/j.ijadhadh.2006.08.001

[24] Dusek, K., Spirkova, M. and Havlicek, I. (1990) Network Formation of Polyurethanes Due to Side Reactions. Macromolecules, 23, 1774-1781.

https://doi.org/10.1021/ma00208a036

[25] O'Connor, A.E. and Kingston, T. (2004) Silyl-Terminated Polyurethanes for Construction Sealants. Journal of ASTM International, 1, 143-155. 
[26] Choffat, F. (2010) Silane-Terminated Polyurethane Polymers. US Patent, No. EP 2221331 A1.

[27] Tan, C., Luona, V., Tirri, T. and Wilen, C.E. (2018) The Synthesis of Low-Viscosity Organotin-Free Moisture-Curable Silane-Terminated Poly(Urethane-Urea)s. Polymers, 10, Article No. 781. https://doi.org/10.3390/polym10070781

[28] Chen, T.K., Tien, Y.I. and Wei, K.H. (2000) Synthesis and Characterization of Novel Segmented Polyurethane/Clay Nanocomposites. Polymer, 41, 1345-1353. https://doi.org/10.1016/S0032-3861(99)00280-3

[29] Petlin, I.A., Sozonov, R.V., Khakimullin, Y.N. and Kurkin, A.I. (2016) The Effect of the Molecular Weight of Polyester on the Properties of Silane Terminated Polyurethane Sealants. Polymer Science Series D, 9, 49-52. https://doi.org/10.1134/S1995421216010172

[30] Kim, K.M., Park, H.W., Shim, G.S., Jang, S.W., Kim, H.J., Chae, G.S. and Lee, J.H. (2019) Mechanical Properties and Decomposition Performance of Peelable Coating Containing UiO-66 Catalyst and Waterborne Silane-Terminated Polyurethane Dispersions. Journal of Materials Science, 55, 2604-2617.

https://doi.org/10.1007/s10853-019-04184-2

[31] Czech, Z. and Milker, R. (2003) Solvent-Free Radiation-Curable Polyacrylate Pressure-Sensitive Adhesive Systems. Journal of Applied Polymer Science, 87, 182-191. https://doi.org/10.1002/app.11303

[32] Subramani, S., Lee, J.M., Kim, J.H. and Cheong, I.W. (2005) One-Pack Cross-Linkable Waterborne Methyl Ethyl Ketoxime-Blocked Polyurethane/Clay Nanocomposite Dispersions. Macromolecular Research, 13, 418-426. https://doi.org/10.1007/BF03218475

[33] Blitz, J. and Little, C. (1999) Fundamental \& Applied Aspects of Chemically Modified Surfaces. Royal Society of Chemistry, Cambridge.

https://doi.org/10.1533/9781845698591

[34] Yuan, Y., Zhang, Y., Fu, X., Kong, W., Liu, Z., Hu, K. and Lei, J. (2017) Molecular Design for Silane-Terminated Polyurethane Applied to Moisture-Curable Pressure-Sensitive Adhesive. Journal of Applied Polymer Science, 134, Article ID: 45292. https://doi.org/10.1002/app.45292

[35] Dodangeh, F., Dorraji, M.S.S., Rasoulifard, M.H. and Ashjari, H.R. (2020) Synthesis and Characterization of Alkoxy Silane Modified Polyurethane Wood Adhesive Based on Epoxidized Soybean Oil Polyester Polyol. Composites Part B: Engineering, 187, Article ID: 107857. https://doi.org/10.1016/j.compositesb.2020.107857

[36] Viswanathan, K., Long, T.E. and Ward, T.C. (2005) Silicon Surface Modification with Trialkoxysilyl-Functionalized Star-Shaped Polymers. Journal of Polymer Science Part A: Polymer Chemistry, 43, 3655-3666. https://doi.org/10.1002/pola.20800

[37] Sen, A.K., Mukherjee, B., Bhattacharyya, A.S., De, P.P. and Bhowmick, A.K. (1992) Kinetics of Silane Grafting and Moisture Crosslinking of Polyethylene and Ethylene Propylene Rubber. Journal of Applied Polymer Science, 44, 1153-1164. https://doi.org/10.1002/app.1992.070440704

[38] Kunze, C., De, C., Klein, J. and De, D. (2013) Curable Compositions Composed of Silanes with Two Hydrolyzable Groups. US Patent, US8563675B2.

[39] Landon, S.J., Dawkins, N.B. and Waldman, B.A. (1997) Hybrid Sealants Demonstrate Enhanced Adhesion to Plastic Substrates. Adhesives and Sealants Industry.

[40] Nomura, Y., Sato, A., Sato, S., Mori, H. and Endo, T. (2008) Synthesis of Novel Moisture-Curable Polyurethanes End-Capped with Alkoxysilane and Use as Solvent-Free Elastic Adhesives. Journal of Applied Polymer Science, 108, 236-244. 
https://doi.org/10.1002/app.27506

[41] Rekondo, A., Fernández-Berridi, M.J. and Irusta, L. (2006) Synthesis of Silanized Polyether Urethane Hybrid Systems. Study of the Curing Process through Hydrogen Bonding Interactions. European Polymer Journal, 42, 2069-2080.

[42] Pröbster, M. (2009) Versatile Backbones for High-Tech Sealants and Adhesives. Adhesion Adhesives \& Sealants, 6, 18-23. https://doi.org/10.1007/BF03250453

[43] Hutchinson, A. and Pagliuca, A. (1996) MS Sealants: A Comparative Study of Performance Properties. Adhesives Age, 39, 16-20.

[44] Cui, S., Luo, X. and Li, Y. (2017) Synthesis and Properties of Polyurethane Wood Adhesives Derived from Crude Glycerol-Based Polyols. International Journal of Adhesion and Adhesives, 79, 67-72. https://doi.org/10.1016/j.ijadhadh.2017.04.008

[45] Yuan, Y., Zhang, Y., Fu, X., Jiang, L., Liu, Z, Hu, K. and Zhou, C. (2016). Silane-Terminated Polyurethane Applied to a Moisture-Curable Pressure-Sensitive Adhesive Using Triethoxysilane. RSC Advances, 6, 83688-83696. https://doi.org/10.1039/C6RA19883J

[46] Leyden, D.E. (1985) Silanes, Surfaces and Interfaces. Gordon \& Breach, New York.

[47] Senichev, A.V. and Borisova, T.Y. (2016) One-Component Polyetherurethane Sealing Glues Cured by Air Moisture. Polymer Science Series D, 9, 273-275. https://doi.org/10.1134/S1995421216030217

[48] Bauer, A., Kammel, T., Pachaly, B., Schfer, O., Schindler, W., Stanjek, V. and Weis, J. (n.d.) New Organofunctional Silanes for Adhesives, Sealants and Spray Foams. In: Auner, N. and Weis, J., Eds., Organosilicon Chemistry V: From Molecules to Materials, Wiley, Hoboken, 527-535. https://doi.org/10.1002/9783527619924.ch85

[49] Bitenieks, J., Meri, R.M., Zicans, J., Berzins, R., Umbraško, J. and Rekners, U. (2016) Rheological, Mechanical and Adhesion Properties of Two Component Adhesive Based on Modified Silyl Terminated Polyether Polymer and Epoxy Resin. IOP Conference Series: Materials Science and Engineering, 111, Article ID: 012018. https://doi.org/10.1088/1757-899X/111/1/012018 